\title{
PERFORMANCE ON THE DROP IMPACT TEST OF THE CONE CAPSULE SHAPED PORTABLE TSUNAMI LIFEBOAT USING PENALTY METHOD CONTACT ANALYSIS
}

\author{
Ahmad Fauzan Zakki*, Suharto Suharto, Dong Myung Bae, Aulia Windyandari \\ Diponegoro University, Indonesia
}

In 2016, the Laboratory of Ship Structures and Construction Diponegoro University organized a research group to develop an alternative hullform for the tsunami lifeboat. The research group proposed a cone capsule shaped portable tsunami lifeboat to support tsunami evacuation system, especially to give a portable protection facility that easily accessed by disable person, senior citizens and children.In order to fulfill the requirement that the lifeboat structure should be able to withstand the impact load, the aimed of the study is focused on the performance of the drop impact test of the developed portable tsunami lifeboat using numerical simulation. The tsunami lifeboat has to maintain its structural integrity when dropped on $3 \mathrm{~m}$ free fall height. The orientation configurations are considered for the numerical analysis includes end drop, side drop and reversed drop. The explicit finite element with penalty method contact analysis is used to evaluate the drop test performance. The results show that the maximum effective stress and plastic strain is found in the side drop condition. It is indicated that the side structure is more vulnerable than the top and bottom structure. The maximum absorbed rupture energy is occurred on the frame structure for reversed drop condition, however it is transmitted effectively to all of the connected frames, outer-shell and inner-shell structures. According to the results of simulation analysis, it can be concluded that the structure of the cone capsule tsunami lifeboat is reliable to withstand the severe load during the tsunami disaster.

Key words: Tsunami lifeboat, Cone capsule shaped geometry, Rupture energy, Structure integrity

\section{INTRODUCTION}

The Sumatra-Andaman Islands Earthquake on December 26, 2004 devastated the North Banda Aceh Coast of the Aceh regionand the surrounding area with the associated massive tsunami. The lessons learned from the tsunami disaster prompted Indonesia National Board for Disaster Management to present guideline that the mitigation management within tsunami disaster should be improved such as the development of tsunami early warning system and the improvement of an access to the tsunami shelter. Meanwhile the Japan Central Disaster Prevention Council has revealed a guideline in September 2011 that a safe place of refuge can be reached within about five minutes by foot, [1]. Therefore, the tsunami shelters and any other protection facilities should be built to reinforce the evacuation measures to help residents escape to a safe place and save their lives when tsunami disaster strikes. Accordingly, the current mitigation tsunami disaster facilities must be expanded into the comprehensive mitigation services by developing alternative human life protection facilities.

Based on the condition, in 2016, the Laboratory of Ship Structures Diponegoro University organized a research group to develop an alternative hullform for the tsunami lifeboat. The research group proposed a cone capsule shaped portable tsunami lifeboat, [2], to support tsunami evacuation system since the basic performance of the shipboard lifeboat is ideal for escaping from a tsunami by floating, especially to give a portable protection facility that easily access by disable person, senior citizens, baby and children.

The requirement of the proposed design of tsunami lifeboat is determined to fulfill the LSA Code which is include self-righting design, unsinkability when flooded and resistance to impact load, [3]. In the case of the resistance to impact load, the lifeboat structure should be able to withstand the lateral impact against the ship's side wall at an impact velocity of $3.5 \mathrm{~m} / \mathrm{s}$, as well as the drop into water from a height of $3 \mathrm{~m}$ without supporting damage that will interrupt its functionality. The additional reinforcement and improvement of the ability to withstand the possible load by tsunami disaster has been given to the proposed tsunami lifeboat. Some advantages have been offered by the portable tsunami lifeboat such as inexpensive cost compared to the other shelter (tsunami towers, tsunami evacuation building, etc.), high flexibility of choice for placement, andimprove the availability level for protection facilities.

In recent years, there have been improvements and developments in design and analyses of lifeboats as lifesaving appliances. Such work began with the mathematical equations formulation of water entryphase on the freefall lifeboat launching using the theories of hydrodynamics, [4], [5]. This was followed by Arai, [6], who provided a mathematical model where impact was evaluated on the concept of a momentum theory, and then Arai introduce the concept to evaluate the acceleration response of the free-fall lifeboat and apply it to assess the seat orientation for the occupants, [7]. Khon 
doker,[8], studied the effect of guide rail on the launching motion of free-fall lifeboat. In the other study, Khondoker compare the launching behavior of free-fall lifeboat using skid and hook,[9]. The influence of falling height and skid angle on the free-fall lifeboat launching behavior in regular waves has been investigated by Karim, [10], [11]. Bae have study on the acceleration response of freefall lifeboat using FSI Analysis,[12], [13].Shibata,[14], used the moving particle semi-implicit to estimate the acceleration response of free-fall lifeboat at the water entry stage. It was found that the reduction of the displacement increased the acceleration response. Zakki, [15] presented fluid structure interaction analysis to develop the hull form of free-fall lifeboat for the evacuation system on offshore platform.In the other study, Zakki investigate the launching parameter on the motion pattern of freefall lifeboat using FSI Analysis,[16]. Guomin Ji, presented the structural integrity assessment of free fall lifeboat launched on the FPSO, [17]. Ringsberg, [18], has investigated free-fall lifeboat structural response using quasi response prediction methods.

In the case of design development of the tsunami evacuation protection system, in 2012, Brahman Industries has developed a floating tsunami shelter known as STATIM (Storm, Tornado and Tsunami Interconnected Modules), [19]. The STATIM give resistant to the initial forces of the acceleration shocks due to a severe tsunami disaster. The STATIM consist of many modular units to create an adjustable length and capacity for application requirement. Alternatively, the "Noah capsule" was developed by N.C.P. Corporation as a floating capsule which is adopted the spherical geometry that provides a strong external surface and elastic to strikes, [20]. Some of works was made by modifying the lifeboat which is mounted on the large vessel. Ishikawajima-Harima Corp (IHI Corp), [21], Tsuneishi facilities and craft co. Itd, [22], and Shigi Shipbuilding, [23] was developing a prototype of Tsunami Lifeboat by providing the reinforcement and improvement the strength of the lifeboat.

The results of previous research indicate that the strength of lifesaving appliances structuresto withstand the possible severe load during the disaster is an important factor for providing the protection in the evacu- ation process.Accordingly the study focused on the performance of drop impact test of the developed portable tsunami lifeboat by adopted the cone capsule geometry using numerical simulation. The tsunami lifeboat has to maintain its structural integrity when dropped on $3 \mathrm{~m}$ free fall height. The orientation configurations are considered for the numerical analysis includes end drop, side drop and reversed drop.

\section{FORMULATION OF MULTI-BODY CONTACT PROB- LEM USING PENALTY METHOD}

Numerical simulations using finite element method (FEM) was used to study the integrity of the structure of tsunami lifeboat. $3 \mathrm{~m}$ drop test is an impact problem which is governed by multi-body contact algorithm. In the finite element method, contact phenomena are interaction between the contacting bodieswhich is treated as a change in boundary conditions. Therefore it is known as the boundary nonlinearities problem. When two separate bodies surface have a contact, they become a contact pair. The forces are transferred based on the physical laws by considering the mechanical properties of the interacting bodies. The interacting bodies are represented by limiting surface and lines of the segments.

The first step to solve the contact problem using FEM is to determine the contact region and the penetrated and penetrating bodies are defined by the user. Then the range within which the program seeks for the contact pairs which is known as a contact tolerance is defined. The maximum distance of nodes detection is determined according to the size of the largest master segment. The first stage of the contact problem solving which is known as kinematics of contact pair is completed since the determination of contact pair is finished. Forces and stresses are generated in the next stage of the calculation procedures.

There are two types of contact algorithms. The first is a node to segment contact algorithm. In the first contact type the penetrated body is described using surfaces which are created by the edge nodes. The surfaces also divide the surface of the body into a subareas multitude. Secondly, the contact kinematic algorithm is defined as
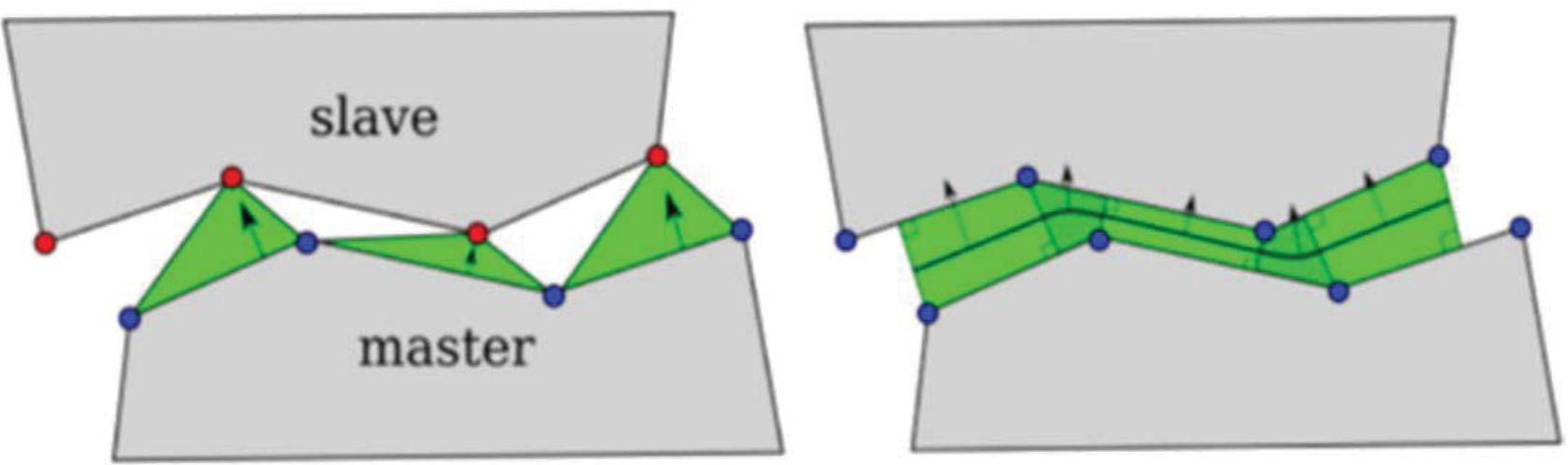

Figure 1: Node to surface contact and segment to segment contact, [24] 


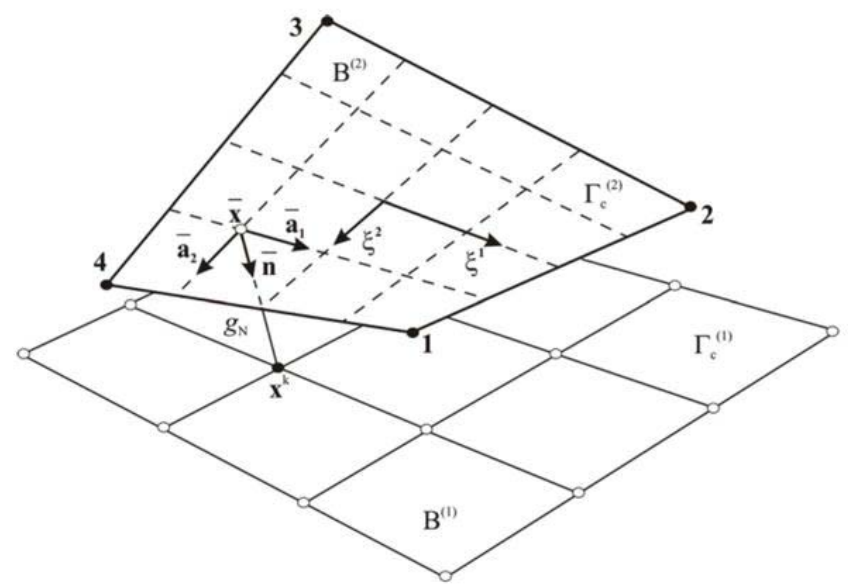

Figure 2: Geometry of three dimensional nodes to surface contact element, [25]

a segment to segment scheme. The representation of the two contact algorithm scheme can be seen in the Fig.1. The defined two different surfaces (master and slave surface) are important, since the nodes which are considered in the contact analysis should be determined. During the calculation process, the distance between surfaces is checked. If the distance smaller than the tolerance number, the contact point and contact force is selected. Contact point selection starts from which adjacent nodes to the node that exceeds the tolerance number is determined. Two bodies are considered as penetrating body (slave) $\mathrm{B}^{(1)}$ and penetrated body (master) $\mathrm{B}^{(2)}$. The contact surface of the body $\mathrm{B}^{(i)}$ is denoted as $\Gamma^{(i)}$. the contact surface $\Gamma^{(i)}$ is the part of the body $B^{(i)}$ which is all material points where contact may occur at any time $t$ are included, Fig. 2. Using the defined notation,the contact surface is denoted as $\Gamma^{(1)}$ and $\Gamma^{(2)}$ for the slave and master slave, respectively. The condition which must be fulfilled is that the master surface could not be penetrated by the slave nodes.

The projection point $(\bar{x})$ of the current position of the slave node $\left(x^{k}\right)$ on the current position of the master surface $\left(\Gamma^{(2)}\right)$ can be defined as:

$$
\frac{\boldsymbol{x}^{k}-\overline{\boldsymbol{x}}\left(\bar{\xi}^{1}, \bar{\xi}^{2}\right)}{\left\|\boldsymbol{x}^{k}-\overline{\boldsymbol{x}}\left(\bar{\xi}^{1}, \bar{\xi}^{2}\right)\right\|} \cdot \overline{\mathbf{a}}_{\alpha}\left(\bar{\xi}^{1}, \bar{\xi}^{2}\right)=0
$$

Where $\overline{\mathbf{a}}_{\alpha}\left(\overline{\xi^{1}}, \overline{\xi^{2}}\right)$ are the tangential base vectors at the point. From the defined projection point, it might be determined the distance betweentheslavenodesandthe master surface. The normal gap and penetration $\left(g_{n}\right)$ of the slave nodes to the master surface can be formulated as follow:

$$
g_{n}=\left(\boldsymbol{x}^{k}-\overline{\boldsymbol{x}}\right) \cdot \overline{\boldsymbol{n}}
$$

Where $\bar{n}$ is the normal vector to the master surface $\Gamma^{(2)}$ at the point $\bar{x}$. The normal vector at the point $\bar{x}$ can be defined as

$$
\bar{n}=\frac{\overline{a_{1}} \times \overline{\mathbf{a}_{2}}}{\left\|\overline{\mathbf{a}_{1}} \times \overline{\mathbf{a}_{2}}\right\|}
$$

The gap formulation on the equation (2) gives the criteria for the contact penetration condition such as: $g_{n}=0$ for perfect contact, $g_{n}>0$ for no contact and $g_{n}<0$ for penetration.

The equations which are presented above have defined the kinematics of contact phenomena in the case of there is no friction between the slave and the master surface. Therefore in the case of friction is considered, the relative tangential displacement should be included.

According to the no sliding problem, to determine the forces that are acting as contact force between the interacting elements, the penalty function method is adopted. In the penalty method, the normal force depends on the penetration and the contact stiffness in the given time step. The pseudo one dimensional spring elements are defined as well as the contact stiffness. Therefore if the slave node (penetrating body) penetrates trough the master surface (penetrated body), the contact force is generated proportionally to the penetration depth to push back the penetrating node.

$$
F_{n}=g_{n} \cdot k
$$

where $F_{n}$ is normal force vector, $g_{n}$ is penetration depth and $k$ is contact stiffness/scaling factor. The magnitude of the contact force $F_{n}$ is estimated by including the work done which is described in the equation of the principle of virtual work which can be written as (5), where, $\Omega$ and $\rho$ are the volume and density of the body $(\alpha) . \sigma_{i, j}{ }^{(\alpha)}$ is the stress tensor and $\delta \varepsilon_{i, j}{ }^{(\alpha)}$ is the virtual strain tensor. $u_{i}^{(\alpha)}, \ddot{u}_{i}^{(\alpha)}$ and $\delta u_{i}^{(\alpha)}$ are the displacement, the acceleration and the virtual displacement tensor in the fixed coordinates respectively. $\mathrm{Fi}^{(\alpha)}$ is a body force tensor. $P_{i}^{(\alpha)}$ is a traction tensor. $\Gamma$ is the area on which $P_{i}^{(\alpha)}$ is acting. $C_{c}$ is contact contribution. Contact contribution for the penalty method is formulated as

$$
C_{c}=\int_{\Gamma}^{\omega}\left(\varepsilon_{N} g_{N} \delta g_{N}+\mathbf{t}_{T} . \delta g_{T}\right) d \Gamma
$$

where, $\delta g_{N}$ and $\delta g_{T}$ are the variations of normal gap and tangential displacement. $\varepsilon_{\mathrm{N}}$ is the normal penalty parameter. $t_{T}$ is tangential stress vector for frictional slip.

$$
\int_{t_{1}}^{t_{2}}\left\{\sum_{\alpha=1}^{2}\left(\int_{\Omega}^{\mathrm{m}} \rho^{(\alpha)} \ddot{u}_{i}^{(\alpha)} \delta u_{i}^{(\alpha)} d \Omega+\int_{\Omega}^{\mathrm{\Xi}} \sigma_{i, j}^{(\alpha)} \delta \varepsilon_{i, j}^{(\alpha)} d \Omega-\int_{\Omega}^{\mathrm{\Gamma}} F_{i}^{(\alpha)} \delta u_{i}^{(\alpha)} d \Omega-\int_{\Gamma}^{\mathrm{E}} P_{i}^{(\alpha)} \delta u_{i}^{(\alpha)} d \Gamma\right)-C_{c}\right\} d t=0
$$


Since the damping effect is neglected, the governing equation of motion in matrices form of the discretized body using finite element method is

$$
[M]\{\ddot{x}\}+\left[K+K_{T N}\right]\{x\}=\left\{F-F_{N}\right\}
$$

where, $[\mathrm{M}]$ is mass matrix, $[\mathrm{K}]$ is stiffness matrix, $\left[\mathrm{K}_{\mathrm{TN}}\right]$ is contact stiffness, $\{F\}$ is external force, $\left\{F_{N}\right\}$ is contact force, $\{\ddot{x}\}$ and $\{X\}$ are the nodal vector of acceleration and acceleration respectively. Since the problem characteristics are non-linear and time dependent, the explicit analy-

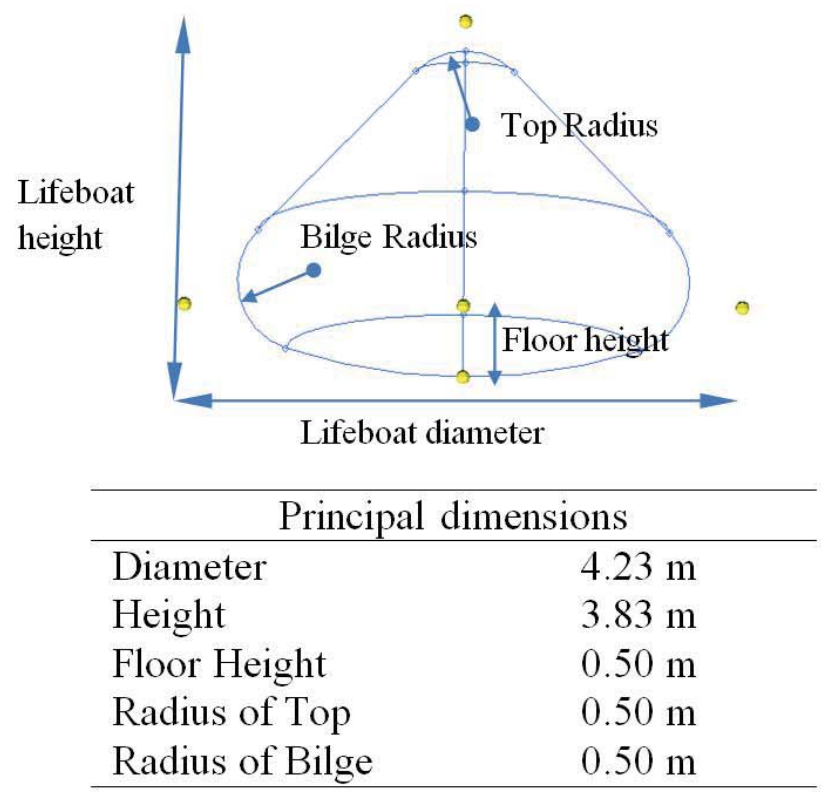

sis is adopted for the numerical calculation. In the explicit analysis, the central difference time integration method is used. The critical parameter to have the convergence solution in the explicit analysis is the time step. The critical limit of the time step can be determined as follow

$$
\Delta t \leq \frac{h_{\text {min }}}{c} c=\sqrt{\frac{E}{\rho}}
$$

where $h_{\text {min }}$ is the smallest element length, $c$ is the courant number, $E$ and $\rho$ are young modulus and material density respectively.

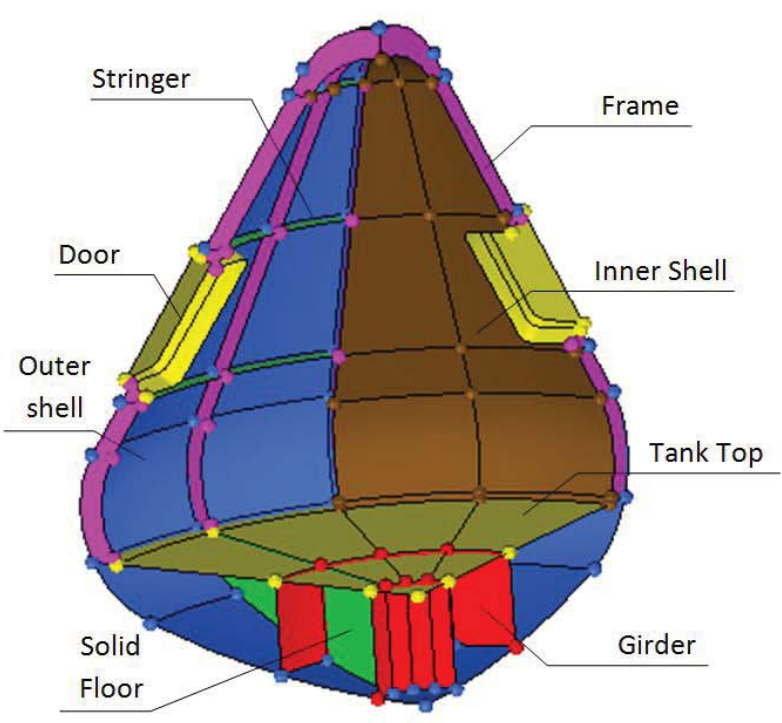

Figure 3: The principal dimensions and structure members of the cone capsule tsunami lifeboat

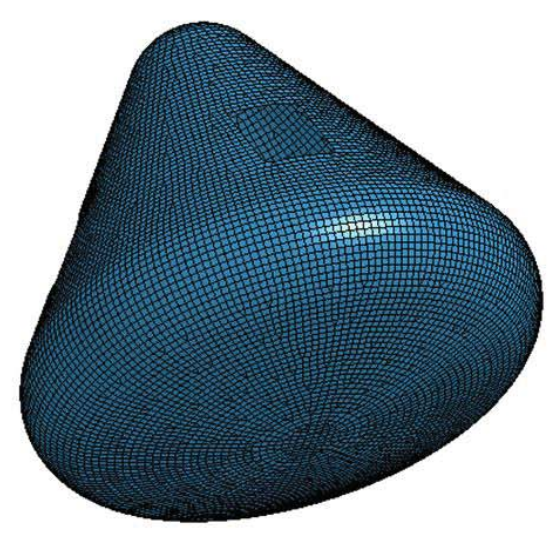

[a]

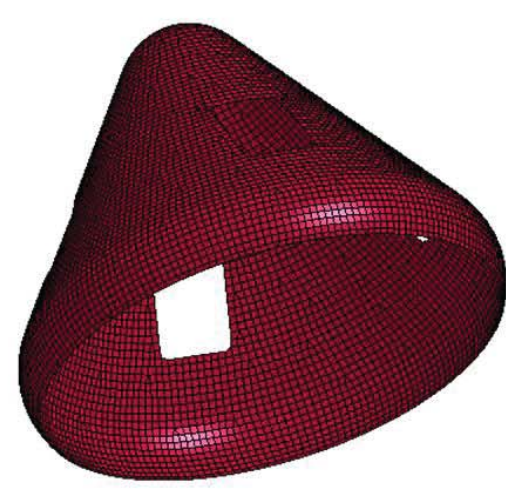

[b]

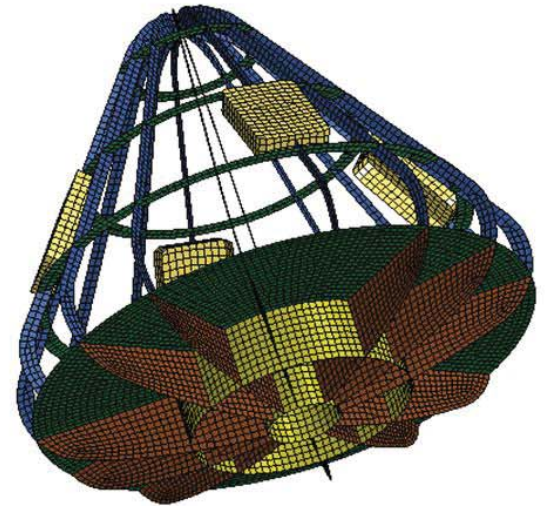

[c]

Figure 4: The tsunami lifeboat FE model: [a] Outer-shell model; [b] Inner-shell model and [c] Frame and bottom structure model 


\section{NUMERICAL SIMULATION MODELING}

\section{Description of finite elements and material modeling}

The development of the cone capsule shaped tsunami lifeboat started with determining the principal dimension of the lifeboat. The principal dimensions are the lifeboat diameter, the height of the lifeboat and the draught of the lifeboat. According to the previous study, the tsunami lifeboat principal dimension and the geometry parameterwere determined as seen on the Fig. 3, [2].

The drop test simulation was conducted using a finite element model to determine the strength of the structure of the cone capsule shaped tsunami lifeboat. Finite element model of the lifeboat is carried out using LSPrepost for the pre/post-processing and LS-DYNA contact algorithm was adopted for the numerical processing. All the structure components wereformulated using Belytschko-Tsay elements with an elasto-plastic material and the defined arbitrary stress versus strain curve and arbitrary strain rate dependency. In the selected material model, the failure based on a plastic strain and the minimum time stepsize also can be defined.Each node of model elements has six degrees of freedom, therefore the translations, rotations and stresses response is automatically described. The developed finite element model consists of 8 parts for the tsunami lifeboat structures, 1 part for the rigid floor, 32890 shell elements, and 30141 numbers of nodes can be seen on the Fig. 4 .

The high rate of loading characteristics might be comprised on the drop test problem of the tsunami lifeboat. Therefore the material model should be able to represent the material behavior under the high strain rate loading. There are several models which are able to model composite materials such as the glass fiber reinforced plastics. Although these material models able to define the orthotropic properties for laminated layers of fiberglass, however the material models is not sufficiently appropriate to support the strain rate effects on the case of dynamics behavior, [26], [27].According to the requirement that the strain rate effects should be able to be defined manually, the selected material model is MAT_PLASTICITY_POLYMER (or MAT 89) card. Although MAT 89 material card is an isotropic material model, in the case of high strain rate phenomena, Tanapornraweekitet. al., [26], declare that the strain rate effects is significantly influence the numerical analysis to have an accurate results than modeling the orthotropic properties of laminated sheet. Therefore an assumption was provided that the adopted GFRP material was arranged to have similar properties as isotropic material. The formula that represents the strain rate effects of the glass reinforced plastics can be seen on the Table 1. Moreover the mechanical properties of glass reinforced plastics in the static environment are determinedfrom the experimental data can be seen on the Table 2 .

Table 1: The strain rate behavior of the glass fiber reinforced plastics in dynamic environment

\begin{tabular}{|c|c|}
\hline Strain rate (per second) & Dynamic elastic modulus, Ed (GPa) \\
\hline$\varepsilon<0.01$ & Ed= Es \\
\hline $0.01 \leq \varepsilon \leq 200$ & Ed= Es+1.055 log $\varepsilon+2.11$ \\
\hline $200 \leq \varepsilon \leq 1700$ & Ed= Es+13.969 log $\varepsilon+27.606$ \\
\hline Strain rate (per second) & Dynamic tensile strength, od (GPa) \\
\hline$\varepsilon<0.01$ & $\sigma d=\sigma s$ \\
\hline $0.01 \leq \varepsilon \leq 90$ & Ed= Es+0.2797 log $\varepsilon+2.11$ \\
\hline $90 \leq \varepsilon \leq 1700$ & Ed= Es+0.6696 log $\varepsilon+27.606$ \\
\hline Strain rate (per second) & Dynamic failure strain, $\varepsilon \_\mathrm{m}^{\wedge} \mathrm{d}$ \\
\hline$\varepsilon<0.01$ & $\varepsilon \_\mathrm{m}^{\wedge} \mathrm{d}=\varepsilon \_\mathrm{m}^{\wedge} \mathrm{s}$ \\
\hline $0.01 \leq \varepsilon \leq 1700$ & $\varepsilon \_\mathrm{m}^{\wedge} \mathrm{d}=\varepsilon \_\mathrm{m}^{\wedge} \mathrm{s}+0.005 \log \varepsilon+0.01$ \\
\hline
\end{tabular}

Table 2: Mechanical properties of glass fiber reinforced plastics

\begin{tabular}{|l|c|}
\hline \multicolumn{2}{|c|}{ GFRP mechanical properties } \\
\hline Longitudinal young modulus, Ex & $65.38(\mathrm{GPa})$ \\
\hline Transverse young modulus, Ey & $15.23(\mathrm{GPa})$ \\
\hline Longitudinal tensile strength, Xt & $1.15(\mathrm{GPa})$ \\
\hline Transverse tensile strength, Yt & $55(\mathrm{MPa})$ \\
\hline Longitudinal compressive strength, Xc & $518(\mathrm{MPa})$ \\
\hline Transverse compressive strength, Yc & $238(\mathrm{MPa})$ \\
\hline
\end{tabular}



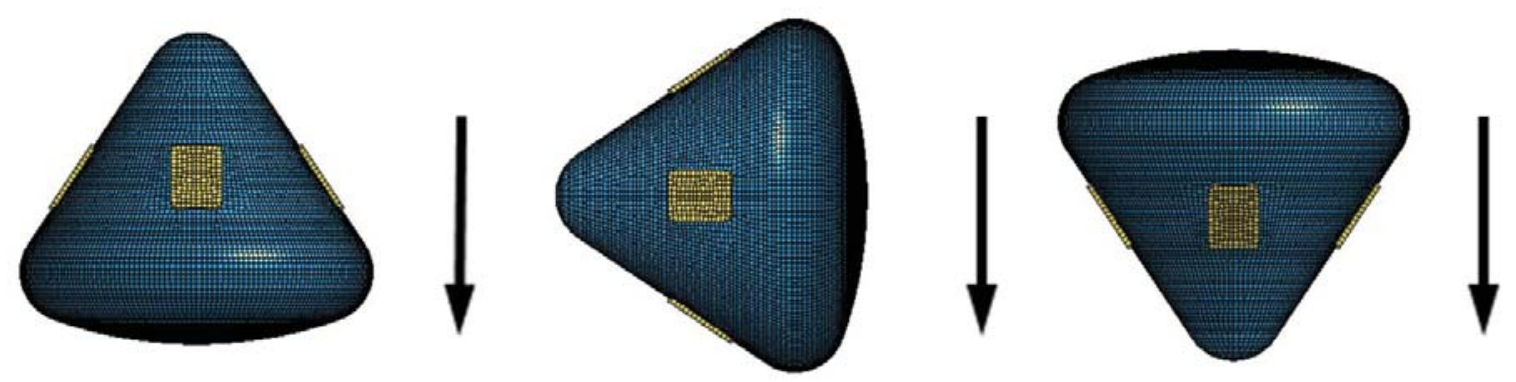

Figure 5: The drop test configurations: bottom drop, side drop and reverse drop

\section{Description of load and boundary conditions}

The configurations of drop condition is considered namely bottom drop, side drop and reversed drop for the performance evaluation of $3 \mathrm{~m}$ drop test of the cone capsule shaped tsunami lifeboat, see Fig. 5. The rigid floor is determined as the drop target which is defined as a rigid body with MAT_RIGID card. The edge of the rigid floor is constrained with the fixed support as the boundary conditions. The load condition is defined as the initial velocity of $7.672 \mathrm{~m} / \mathrm{s}$ which is equivalent to the $3 \mathrm{~m}$ freefall height velocity before crash with the rigid floor. The given load as an initial velocity may reduce the computation time, since the numerical calculations do not have to compute the simulation of free-fall phase. Furthermore the running simulation is determined to capture the crash event within $80 \mathrm{~ms}$. The penalty contact method is adopted using CONTACT_NODES_TO_SURFACE card with no sliding contact option is selected for the contact definition of the tsunami lifeboat and rigid floor.
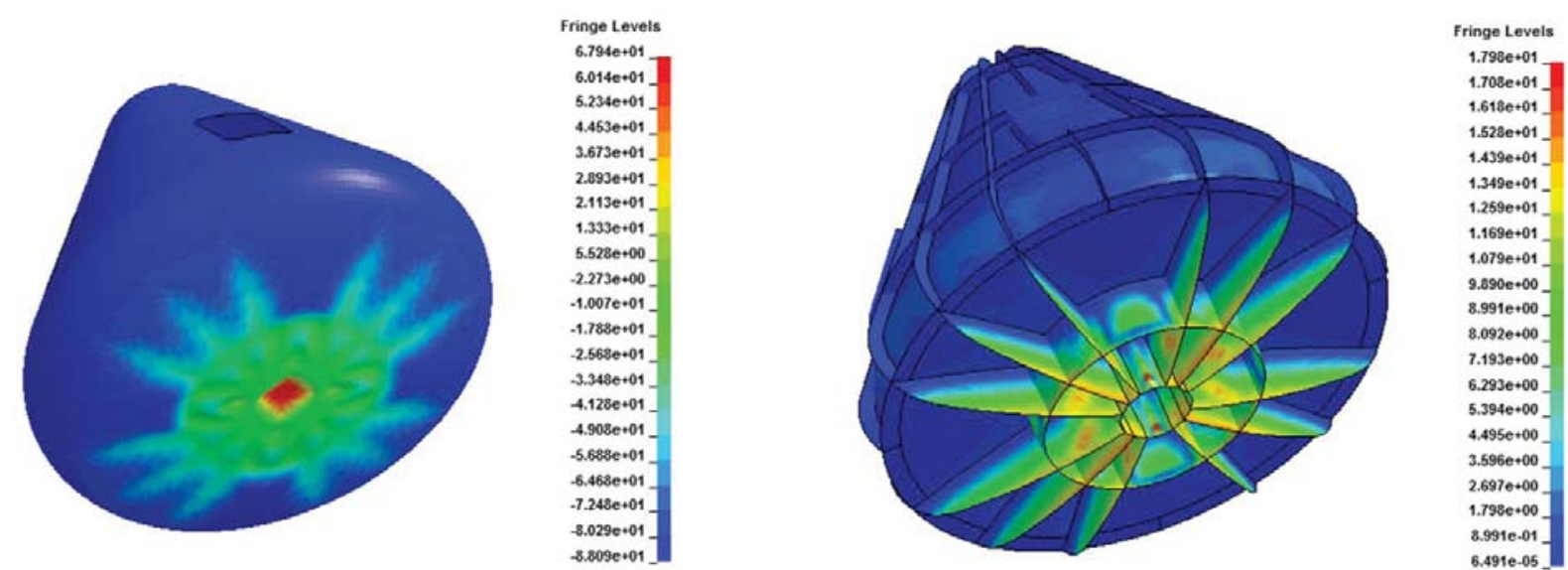

Figure 6: Deformation of outer-shell and frame structure on the bottom drop condition
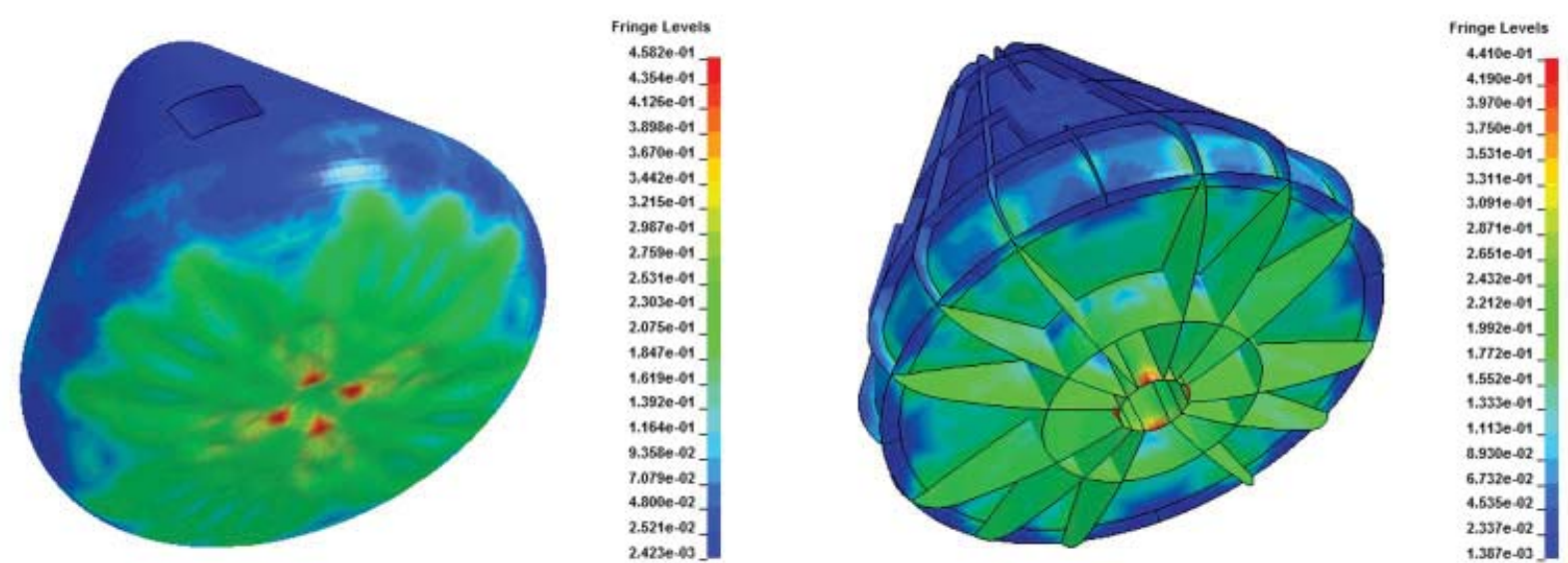

Figure 7: Effective stress (Von Mises) of outer-shell and frame structure on the bottom drop condition 

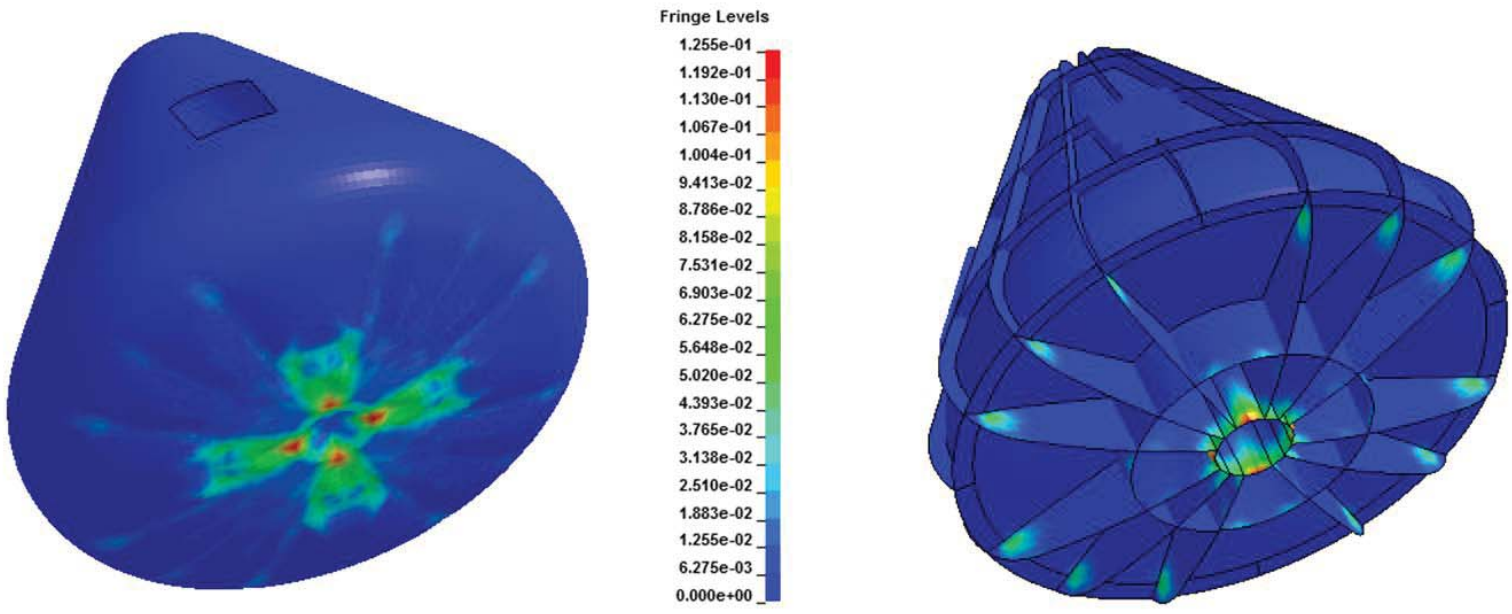

Fringe Levels
$1.171 \mathrm{e}-01$
$1.113 \mathrm{e}-01]$
$1.054 \mathrm{e}-01$
$9.957 \mathrm{e}-02$
$9.371 \mathrm{e}-02$
$8.785 \mathrm{e}-02$
$8.200 \mathrm{e}-02$
$7.614 \mathrm{e}-02$
$7.028 \mathrm{e}-02$
$6.443 \mathrm{e}-02$
$5.857 \mathrm{e}-02$
$5.271 \mathrm{e}-02$
$4.685 \mathrm{e}-02$
$4.100 \mathrm{e}-02$
$3.514 \mathrm{e}-02$
$2.928 \mathrm{e}-02$
$2.343 \mathrm{e}-02$
$1.757 \mathrm{e}-02$
$1.171 \mathrm{e}-02$
$5.857 \mathrm{e}-03$
$0.000 \mathrm{e}+00$

Figure 8: Plastic Strain of outer-shell and frame structure on the bottom drop condition

\section{RESULTS AND DISCUSSIONS}

The cone capsule tsunami lifeboat structural response under $3 \mathrm{~m}$ drop test for three different drop type configurations was simulated using post-processing software. The integrity of the lifeboat structure was analyzed and investigated considering the various parameters which is includes the effective stress (Von-Mises stress), the structure deformation, loss of watertight integrity and the rupture energy which is absorbed by the structure members.

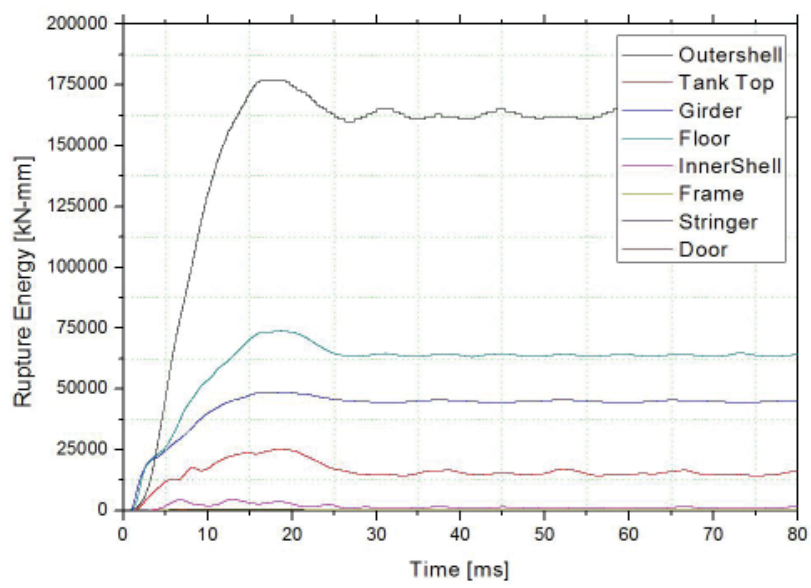

Figure 9: The rupture energy of structure parts on the bottom drop

\section{Structural response of the Bottom-drop Condition}

The simulation result of structure deformation of cone capsule tsunami lifeboat after bottom drop test condition is shown in Fig. 6. It can be identified that the bottom plate of the outer shell is deformed and the bottom girderhave buckled. The rupture energy which is absorbed by the structural parts of the tsunami lifeboat is presented in the Fig. 9. It might be seen that the maximum rupture energy is absorbed by the outer shell, regarding the purpose of the outer shell for which this is provided.
The maximum effective stress obtained on the outer shell of tsunami lifeboat is $458 \mathrm{MPa}$, see Fig. 7. The outer-shell provides a watertight boundary which encloses the cabin. The bottom part failure of the outer shell can cause the leakage of tsunami lifeboat hull which may influence the stability performance. However the simulation result shows that the maximum effective stress is lower than the ultimate strength of the selected material.

The plastic strain is observed at the bottom deflected part as the lifeboat undergoes impact phase, see Fig. 8. The maximum plastic strain of the bottom part is estimated to be $12.55 \%$. The maximum deformation is $67.94 \mathrm{~mm}$ which is equivalent to $13.58 \%$ the height of lifeboat double bottom, see Fig.6. It may be noted that height of the double bottom is the distance between bottom plates with the tank top that is required to reduce the risk of compartment flood due to grounding incident. The large displacement of the bottom plate and the tank top due to the impact load may cause plastic deformations which influence the integrity of the lifeboat structure.

\section{Structural response of the Side-drop Condition}

The analysis of side drop is required in order to study the collision the tsunami lifeboat with any kind of wall shaped object. However the rigid wall was considered as the struck object of the drop test simulation. According to the result of the numerical simulation it can be seen that the side part of the outer shell structure has deflected due to collision with the rigid wall. The frame and the bilge strake are deformed and the tank top is buckled, see Fig. 10. The absorbed of the collision energy can be seen on the Fig. 14. The maximum collision energy is absorbed by the side part of the outer shell and the tank top of the tsunami lifeboat, and it can be explained since the structural part is located on the vicinity of the impact. In the side drop condition the maximum effective stress is shown on the side frame of the tsunami lifeboat. The stress distribution of the tsunami lifeboat under the side drop can be seen on the Fig. 11. 

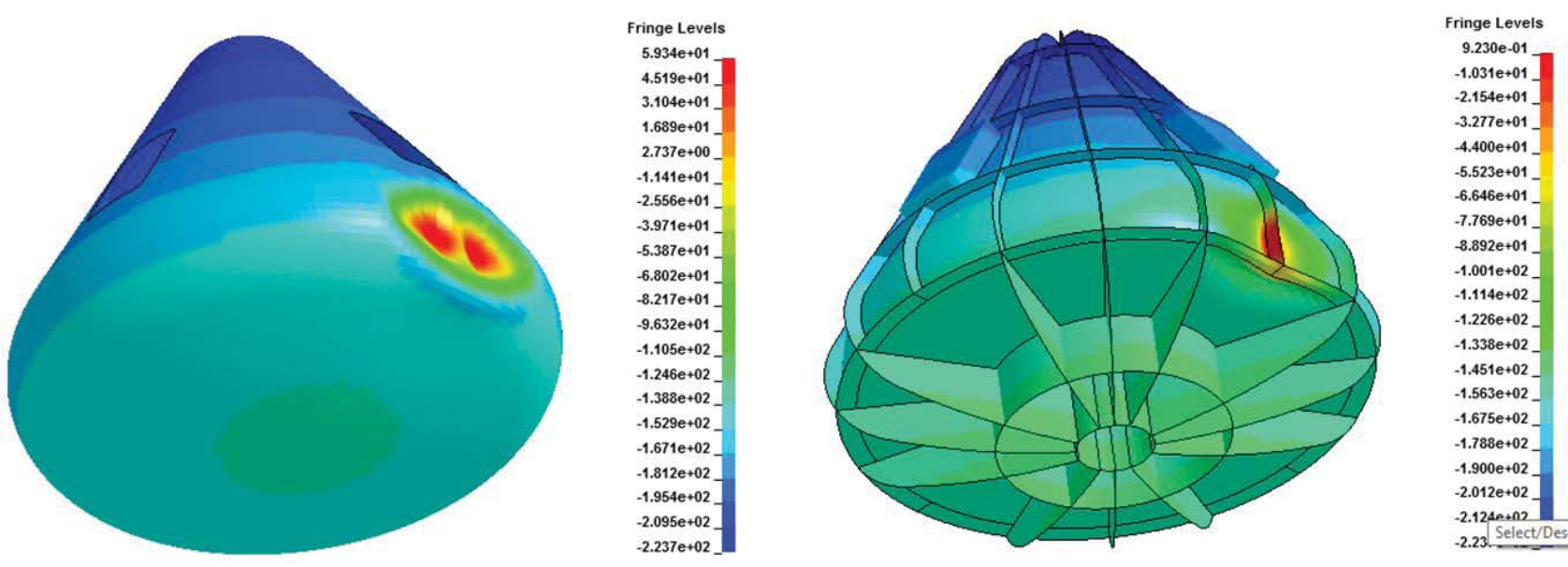

Figure 10: Plastic Strain of outer-shell and frame structure on the bottom drop condition
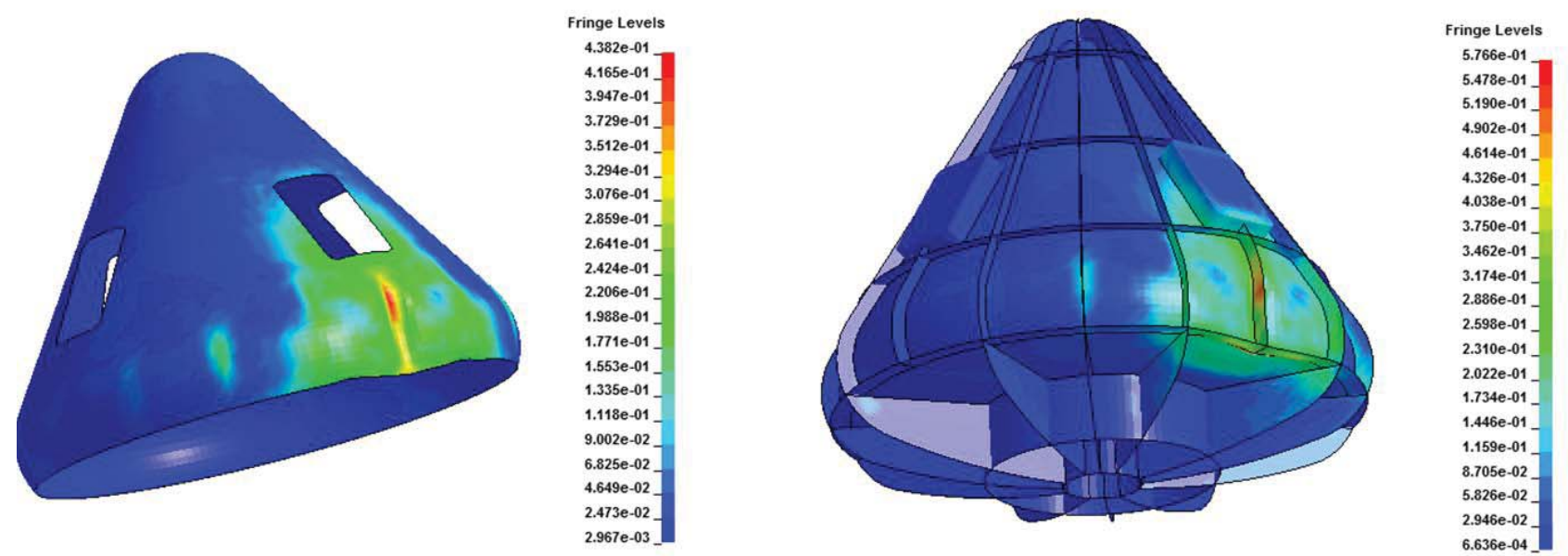

Figure 11: Effective stress (Von Mises) of inner-shell and frame structure on the side drop condition
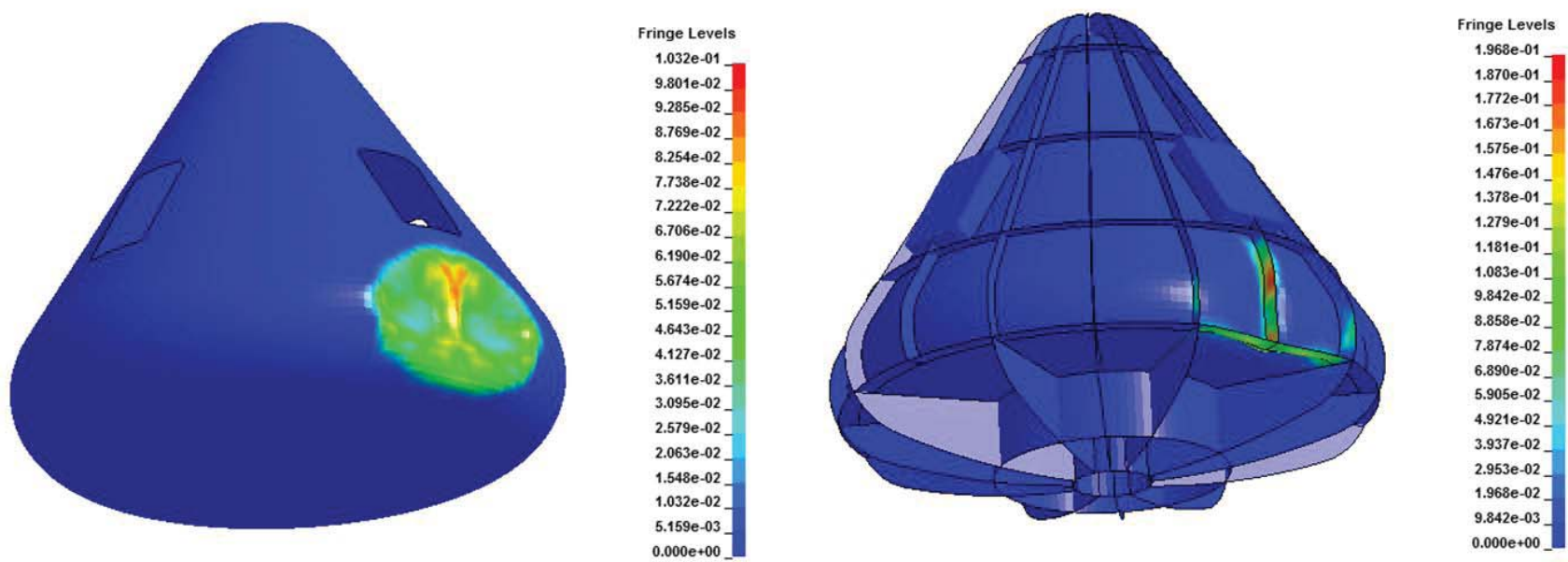

Figure 12: Plastic Strain of outer-shell and frame structure on the side drop condition 

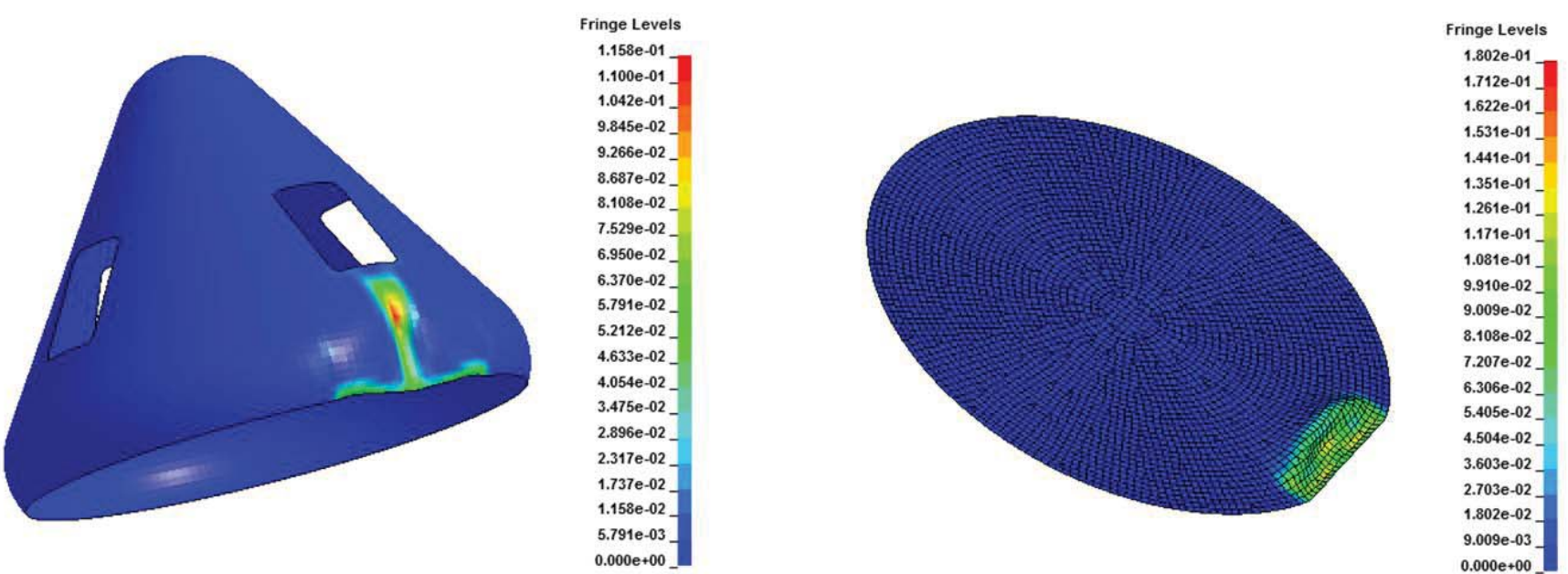

Figure 13: Plastic Strain of outer-shell and frame structure on the side drop condition

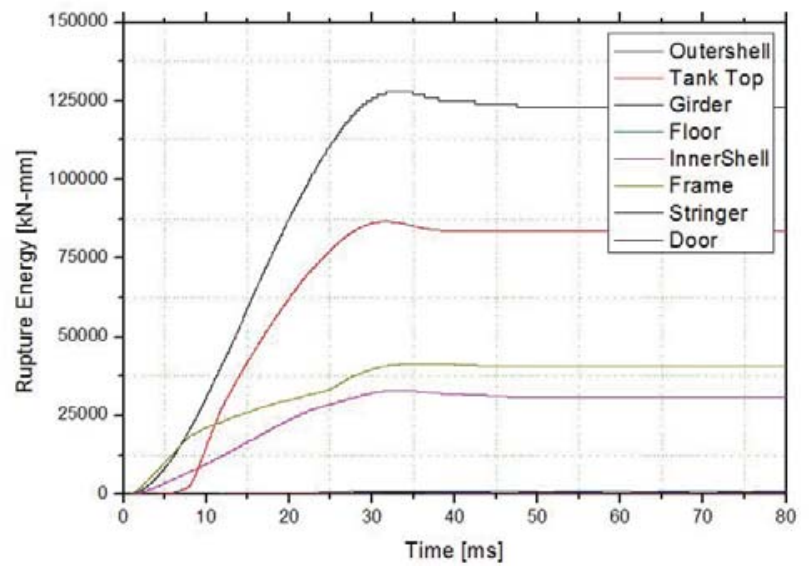

Figure 14: The rupture energy of structure parts on the side drop

It is also obtained that the stress in the inner shell is occurred, since the structure is deflected because of the pressure which is caused by the bended side frame. The effective stress in the inner shell is $438.2 \mathrm{MPa}$, and the maximum effective stress of $576 \mathrm{MPa}$ was obtained on the frame. Although the occurred effective stress is relatively large, however the structure members are still able to maintain the structure integrity.

In the case of plastic strain, the simulation result shows that the plastic strain is observed on the deformed side wall structure. The maximum plastic strain is $19.68 \%$ which can be obtained on the side frame component, see Fig. 12. Although the deformation is started at the bilge part, however the side frame creates a rigid connection on the side wall. Therefore the stress is concentrated on the frame structure that caused plastic bended deformation. Instead of the outer shell and side frame, the plastic strain also obtained in the inner shell and the buckled tank top. The plastic strain in the inner shell and the buckled tank top are $11.58 \%$ and $18.02 \%$ respectively, Fig 13.

\section{Structural response of the Side-drop Condition}

The final configuration of the drop test is a reversed drop condition. The reverse drop condition represented the strength of the lifeboat structure due to the impact load induced by any object that strikes the top of the cone capsule of the tsunami lifeboat. The gross deformation of the tsunami lifeboat might be seen on the Fig. 15. The top parts of the lifeboat structure are deformed. According to the simulation results, the top structures have structure integrity better than the side and bottom structures. The interconnected frames are produced significant stiffness to the outer-shell and inner-shell structures. Therefore the deformation occurred is smaller than the deformation on the bottom-drop and side-drop conditions. The maximum rupture energy is absorbed by the frames structure, see Fig. 18. Relating to the absorbed rupture energy graphs, it is indicated that the frames give an effective strength to withstand the impact load on the top part of the lifeboat.

The stress distribution during the reverse-drop condition has shown in the Fig. 16. The cone geometry of the top part has concentrated the impact load to the peak point of the outer-shell. However the concentrated impact load had been absorbed and distributed effectively to the inner-shell by the interconnected frames. Therefore the interconnected frames maximum effective stress is obtained of $563 \mathrm{MPa}$. The maximum effective stress of outer-shell and inner-shell are $513 \mathrm{MPa}$ and $360 \mathrm{MPa}$, respectively. According to the obtained maximum effective stress, it might be explain that the structures failure do not occurred and the structure integrity is maintained.

Fig. 17 has shown the plastic strain in the top part of the lifeboat structure. The maximum plastic strain of $17.81 \%$ is observed in the top region of the frame structure. The plastic strain can be found also in the frame and inner shell structure. The magnitudes of the plastic strain of the outer-shell and inner shell are $15.25 \%$ and $7.8 \%$, respectively. 

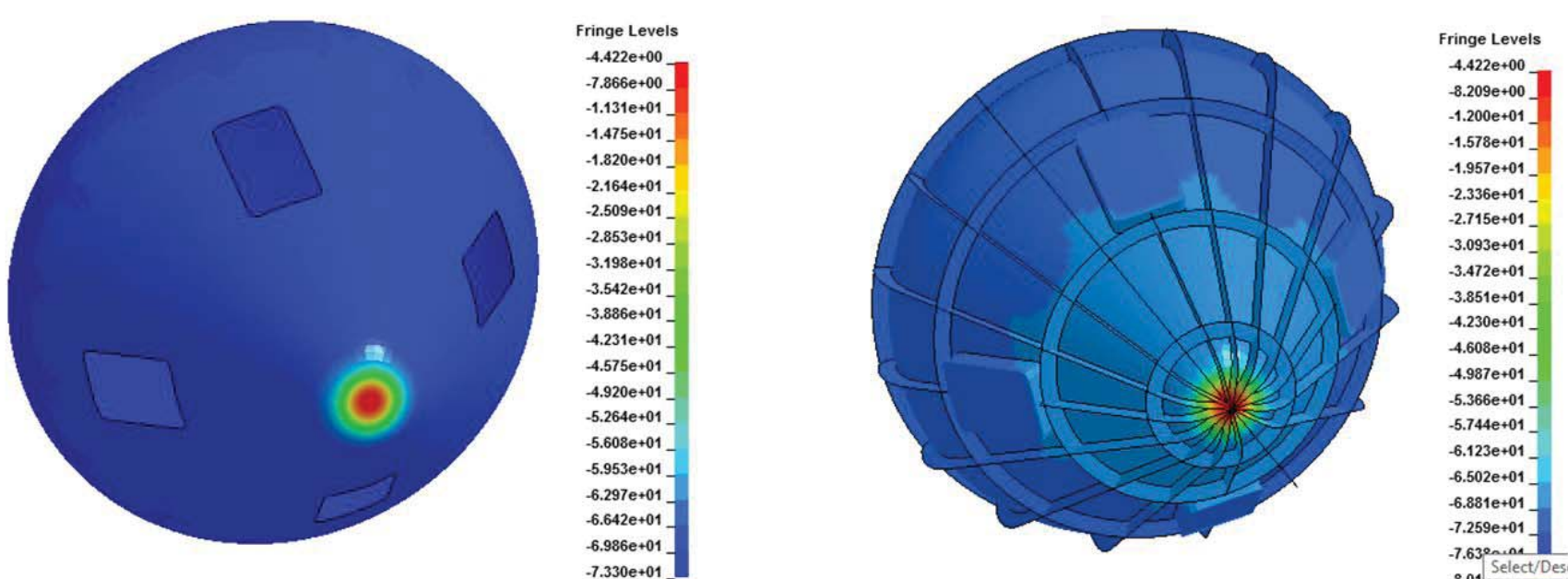

Figure 15: Deformation of outer-shell and frame structure on the reverse drop condition
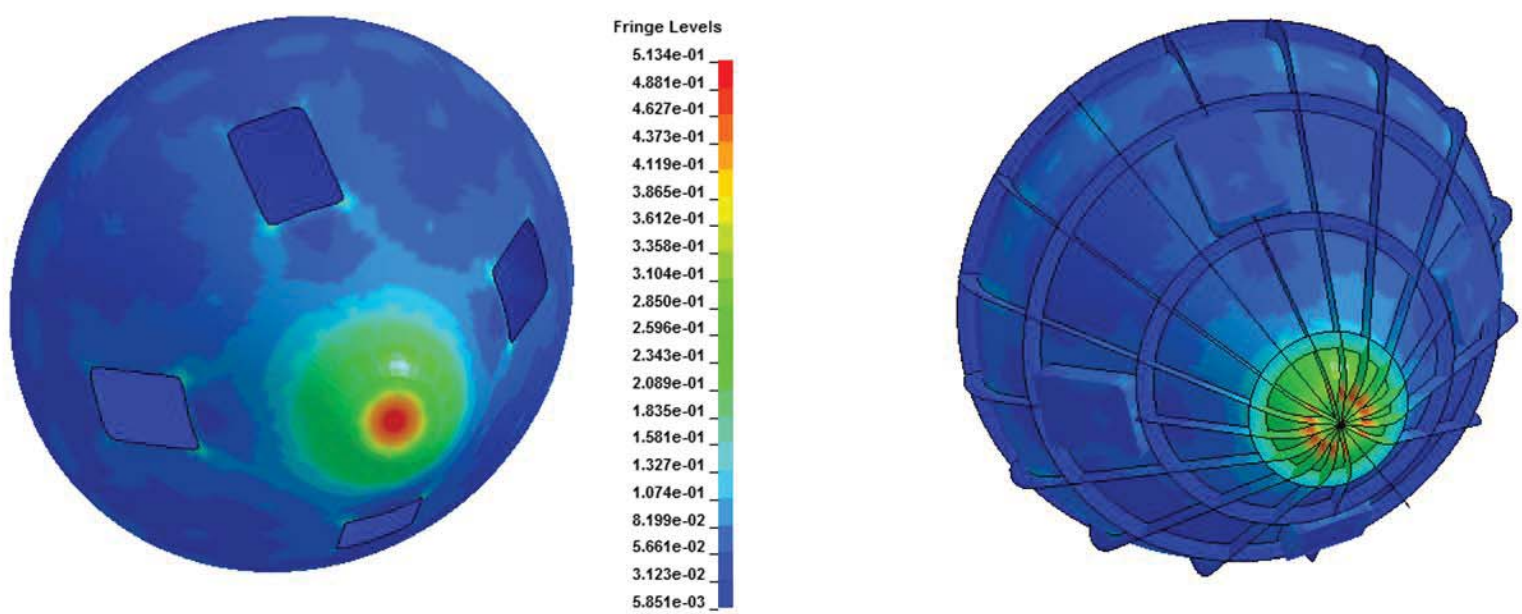

$\left.\begin{array}{c}\text { Fringe Levels } \\ 5.633 \mathrm{e}-01 \\ 5.352 \mathrm{e}-01 \\ 5.071 \mathrm{e}-01 \\ 4.790 \mathrm{e}-01 \\ 4.509 \mathrm{e}-01 \\ 4.228 \mathrm{e}-01 \\ 3.948 \mathrm{e}-01 \\ 3.667 \mathrm{e}-01 \\ 3.386 \mathrm{e}-01 \\ 3.105 \mathrm{e}-01 \\ 2.824 \mathrm{e}-01 \\ 2.543 \mathrm{e}-01 \\ 2.262 \mathrm{e}-01 \\ 1.982 \mathrm{e}-01 \\ 1.701 \mathrm{e}-01 \\ 1.420 \mathrm{e}-01 \\ 1.139 \mathrm{e}-01 \\ 8.582 \mathrm{e}-02 \\ 5.774 \mathrm{e}-02 \\ 2.965 \mathrm{e}-02 \\ 1.565 \mathrm{e}-03\end{array}\right]$

Figure 16: Effective stress (Von Mises) of outer-shell and frame structure on the bottom drop condition
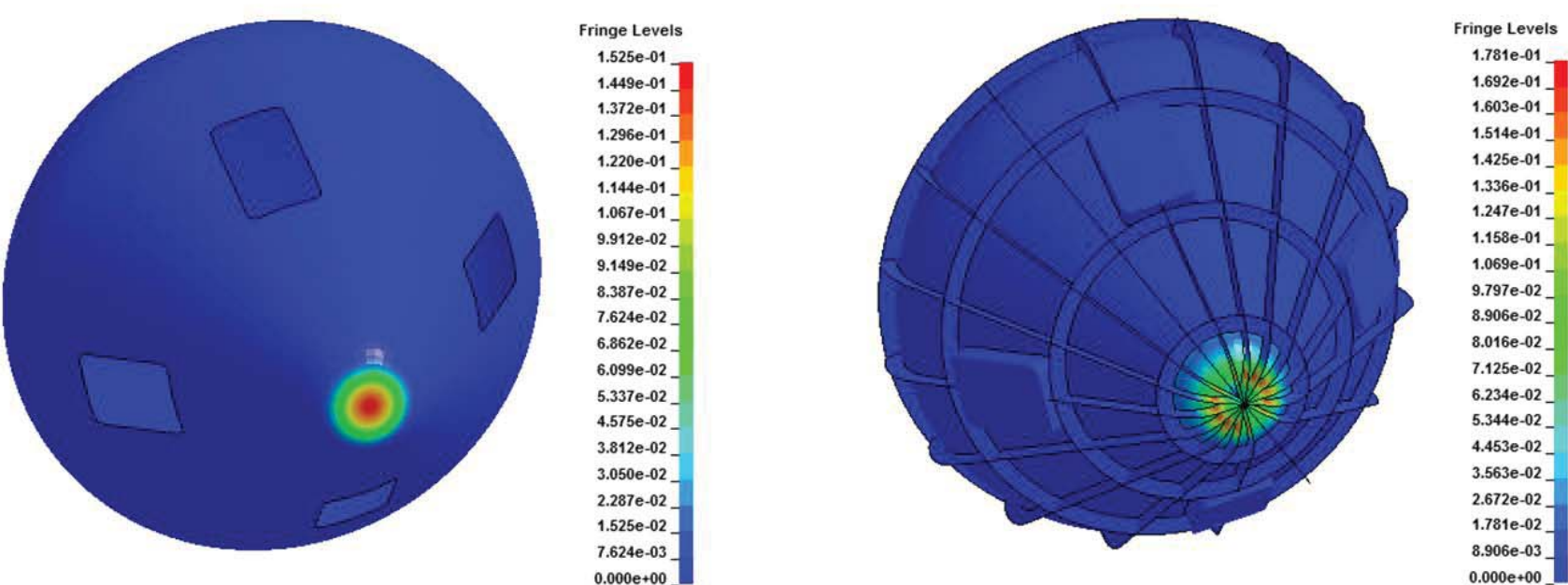

Figure 17: Plastic Strain of outer-shell and frame structure on the bottom drop condition 
Table 3: The summary of the $3 m$ drop test results

\begin{tabular}{|l|c|c|c|}
\hline \multicolumn{1}{|c|}{ Parameters } & Bottom Drop & Side Drop & Reversed Drop \\
\hline $\begin{array}{l}\text { Maximum effective stress } \\
\text { (Von Mises Stress) }\end{array}$ & $458 \mathrm{MPa}$ & $576 \mathrm{MPa}$ & $563 \mathrm{MPa}$ \\
\hline $\begin{array}{l}\text { Maximum Deformation } \\
\text { (Z-Displacement) }\end{array}$ & $67.94 \mathrm{~mm}$ & $59.34 \mathrm{~mm}$ & $4.42 \mathrm{~mm}$ \\
\hline $\begin{array}{l}\text { Maximum absorbed } \\
\text { rupture energy }\end{array}$ & $\begin{array}{c}176870 \text { Joules } \\
\text { (on Outer-shell) }\end{array}$ & $\begin{array}{c}128080 \text { Joules } \\
\text { (on Outer-shell) }\end{array}$ & $\begin{array}{c}209940 \text { Joules } \\
\text { (on Frames) }\end{array}$ \\
\hline Maximum plastic strain & $12.55 \%$ & $19.68 \%$ & $17.81 \%$ \\
\hline Watertight failure & Not Occurred & Not Occurred & Not Occurred \\
\hline
\end{tabular}

Since the entire drop test conditions have been explained, the summary of the $3 \mathrm{~m}$ drop test result could be seen on the Table 3.

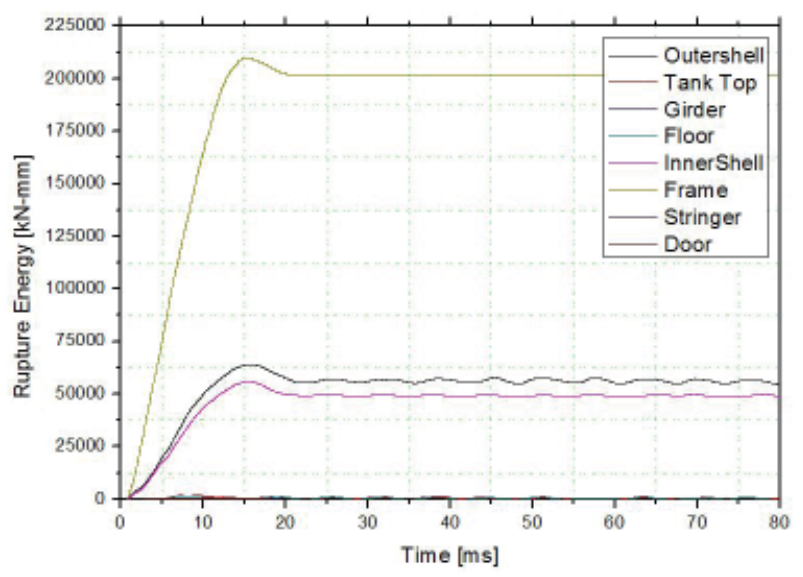

Figure 18: The rupture energy of structure parts on the reverse drop

\section{CONCLUSIONS}

The cone capsule shaped tsunami lifeboat $3 \mathrm{~m}$ drop performance was analyzed using penalty contact algorithm in explicit finite element method. It was obtained that the maximum effective stress (Von Mises stress) of the outer shell is smaller than the ultimate stress limit of the lifeboat material in the entire drop test conditions. The maximum effective stress of $576 \mathrm{MPa}$ is found in the side drop condition. The maximum plastic strain of $19.68 \%$ is also obtained in the frame structures for the side drop condition. It is indicated that the side structure is more vulnerable than the top and bottom structure.

In the case of impact energy which influenced the integrity of the lifeboat structure, the maximum absorbed rupture energy of 209940 Joules is occurred on the frame structure for reversed drop condition. Although the significant rupture energy is exerted on the frame structures, however the effective stress of $563 \mathrm{MPa}$ which is occurred on the frame structure is smaller than the tensile strength of the tsunami lifeboat material. It is indicated that the rupture energy has been transmitted effectively to all of the connected frames, outer-shell and inner-shell structures.

According to the results of simulation analysis for the $3 \mathrm{~m}$ drop test on the cone capsule tsunami lifeboat using penalty contact method contact algorithm, the lifeboat structure and watertight integrity is maintained for the entire drop test configuration. It can be concluded that the structure of the cone capsule tsunami lifeboat is reliable to withstand the severe load during the tsunami disaster.

\section{REFERENCES}

1. Central Disaster Management Council. (2011).Report of the Committee for Technical Investigation on Countermeasures for Earthquakes and tsunamis Based on the Lessons Learned from the 2011 off the Pacific coast of Tohoku Eartquake.

2. Zakki, A. F., Suharto and Windyandari, A. (2018). The Evaluation of Cone Capsule as an Alternative Hull formfor Portable Tsunami Lifeboat to Support Evacuation Systemin the Coastal Regions and Small Islands. IOP Conf. Series: Earth and Environmental Science, vol. 135, 01-08, DOI: 10.1088/17551315/135/1/012006

3. IMO. (1996). International Life-Saving Appliance (LSA) Code.

4. Boef, W. J. C. (1992). Launch and impact of freefall lifeboats. Part I. Impact theory.Ocean Engineering,vol. 19, no. 2, 119-138, DOI: 10.1016/00298018(92)90011-R

5. Boef, W. J. C. (1992).Launch and impact of free-fall lifeboats. Part II. Implementation and applications. Ocean Engineering,vol. 19, no. 2, 139-159, DOI: 10.1016/0029-8018(92)90012-S

6. Arai, M., Khondoker, M. R. H. and Inoue, Y. (1995). Water Entry Simulation of Free Fall Lifeboat, 1st report: Analysis of Motion and Acceleration.Journal of The Society of Naval Architects of Japan,vol. 178, 193-201. 
7. Arai, M., Khondoker, M. R. H. and Inoue, Y. (1996). Water Entry Simulation of Free Fall Lifeboat, 2nd Report: Effects of Acceleration on the Occupants.Journal of The Society of Naval ArchitectS of Japan,vol. 179, 205-211.

8. Khondoker, M. R. H. (1998). Effects of launching parameters on the performance of a free-fall lifeboat. Naval Engineers Journal, vol. 110, no. 4, 67-73, DOI:10.1111/j.1559-3584.1998.tb02612.x.

9. Khondoker, M. R. H. and Arai, M. (2000). A comparative study on the behaviour of free-fall lifeboat launching from a skid and from a hook.Proceedings of the Institution of Mechanical Engineers, Part C: Journal of Mechanical Engineering, vol. 214, no. 2, 359-370, DOI: 10.1243/0954406001523029.

10. Karim,M., Iqbal, K., Khondoker, M. and Rahman,S. (2009). Numerical investigation into the effect of launch skid angle on the behaviour of free-fall lifeboat in regular waves.Transactions of the Royal Institution of Naval Architects Part B: International Journal of Small Craft Technology, vol. 151.

11. Karim, M., Iqbal, K., Khondoker, M. and Rahman, S. (2011).Influence of falling height on the behavior of skid-launching free-fall lifeboat in regular waves. Journal of Applied Fluid Mechanics,vol. 4, no. 1, 77-88.

12. Bae, D. M., Zakki, A. F., Kim, H. S. and Kim, J. G. (2010). Estimation of Acceleration Response of Freefall Lifeboat usingFSI Analysis Technique of LS-DYNA Code.Journal of the Society of Naval Architects of Korea, vol. 47, no. 5, 681-688, DOI: 10.3744/SNAK.2010.47.5.681.

13. Bae, D. M. and Zakki, A. F. (2011). Comparisons of Multi Material ALE and Single Material ALE in LS-DYNA for Estimation of Acceleration Response of Free-fall Lifeboat.Journal of the Society of Naval Architects of Korea, vol. 48, no. 6, 552-559, DOI: 10.3744/SNAK.2011.48.6.552.

14. Shibata,K., Koshizuka, S., Sakai, M., Tanizawa, K. and Ota, S. (2013). Numerical Analysis of Acceleration of a Free-fall Lifeboat Using the MPS Method. International Journal of Offshore and Polar Engineering, vol. 23, no. 4, 279-285.

15. Zakki, A. F., Windyandari, A. and Bae, D. M. (2016). The Development of New Type Free Fall Lifeboat using Fluid Structure Interaction Analysis.Journal of Marine Science and Technology-Taiwan, vol. 2016, no. 3, 575-580, DOI: 10.6119/JMST-015-1126-1.

16. Zakki, A. F., Windyandari, A. and Bae, D. M. (2015). The Investigation of Launching Parameters on the Motion Pattern of Freefall Lifeboat Using FSI Analysis.Procedia Earth and Planetary Science, vol. 14, 110-117, DOI: 10.1016/j.proeps.2015.07.091.

17. Ji, G., Berchiche, N., Fouques, S., Sauder, T. and Reinholdtsen, S.-A. (2015). Integrity Assessment of a Free-Fall Lifeboat Launched From a FPSO.ASME 2015 34th International Conference on Ocean, Offshore and Arctic Engineering.
18. Ringsberg, J., Heggelund,S., Lara,P., Jang,B.-S. and Hirdaris, S. (2017). Structural response analysis of slamming impact on free fall lifeboats.Marine Structures, vol. 54, 112-126, DOI: 10.1016/j.marstruc.2017.03.004.

19. Brahman Industries. Storm, Tornado and Tsunami Interconnected Modules Shelters (STATIM) Shelter Systems. Brahman Industries. from https://www. statimshelter.com/. Accessed on 2017-11-04.

20. The Guardian. Japanese 'Noah's ark' disaster capsule goes on sale. Cosmo Engineering Company. from https://www.theguardian.com/world/2011/ sep/30/japanese-noahs-ark-disaster-capsule. Accessed on 2015-11-5.

21. Takahiro, S., Kazuo,S., Ryosuke, S., Kenjiro, Y., Hiroyuki, S. and Akio, I. (2014). Development of a Prototype Tsunami Lifeboat.IHI Engineering Review, vol. 46, no. 2, 11-20.

22. Tsuneishi Facilities and Craft. Tsunami Lifeboat Guidelinesapproval granted for the TTS80Floating Aluminum Tsunami Shelter. Tsuneishi Facilities and Craft Co. Ltd. from https://www.tsuneishi-g.jp/english/news/press/2014/09/1674. Accessed on 201512-05.

23. Shigi Shipbuilding. Lifeboats that are Resilient against Tsunami and Floods LIFE SEEDER). Shigi Shipbuilding Co. Ltd. from http://www.shigi-sb.co.jp/ en/products/tsunami.html. Accessed on 2015-12-3.

24. Yaztrebov, V. A. (2011). Computational Contact Mechanics.Paris: Ph. D. dissertation.

25. Vulovic,S., Zivkovic, M., Grujovic, N. and Slavkovic, R. (2007). A comparative Study of Contact Problems Solution Based on the Penalty and Lagrange Multiplier Approaches.Journal of the Serbian Society for Computational Mechanics,vol. 1, no. 1, 174-183.

26. Tanapornraweekit, G., Haritos,N., Mendis, P. and Ngo, T. D. (2010). Finite Element Simulation of FRP Strengthened Reinforced Concrete Slabs Under Two Independent Air Blasts. International Journal of Protective Structures, vol. 1, no. 4, 469-488, DOI: 10.1260/2041-4196.1.4.469.

27. Tanapornraweekit, G., Haritos, N., Mendis, P. (2011). Behavior of FRP-RC Slabs under Multiple Independent Air Blasts.Journal of Performance of Constructed Facilities, vol. 25, no. 5, 433-440, DOI: 10.1061/ (ASCE)CF.1943-5509.0000191.

Paper submitted: 22.11.2018.

Paper accepted: 17.03.2019.

This is an open access article distributed under the CC BY-NC-ND 4.0 terms and conditions. 